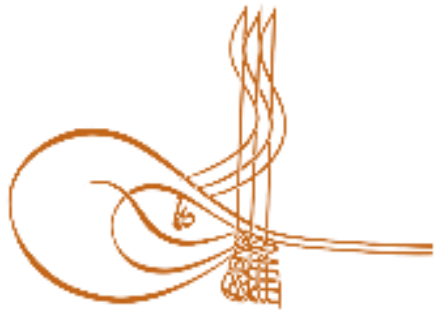

www.turkishstudies.net/social
Turkish Studies - Social Sciences

eISSN: $2667-5617$

Research Article / Araştırma Makalesi

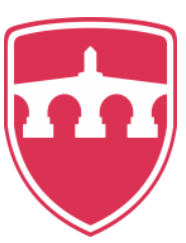

INTERNATIONAL

BALKAN

UNIVERSITY

Sponsored by IBU

\title{
Arap Dünyasında Tercüme Faaliyetleri
}

Translation Activities In The Arabic World

Mehmet Bölükbaşı*

\begin{abstract}
Translation is an activity that has been done since the existence of humanity. Translation, from a different language to the mother language is a complex and difficult process. The important thing in translation is to translate the translated text to the target language with the closest meaning. There are many factors affecting translation, the most important of which is to know the culture in which the translated work is written and find it in the most appropriate word and transfer it to the target language. Translation, is an ongoing activity and throughout history the need for translation has arisen to provide communication between communities through economic, cultural relations and conquests they have provided communication between them through translation. Human beings have noticed that translation has been important since its existence, and has used translation to deal with communities from other cultures. Translation activities to resolve conflicts that may arise between different languages and cultures and appeared in the $2^{\text {nd }}$ century BC. In the Arabs, the first foundations of translation activities were laid during the Umayyads, thanks to the personal curiosity of the people who ruled the state. In this period, translation activities could not go beyond the interest of statesmen in translation. It was a period when the translation of historical works belonging to the old periods was done. The development of translation activities in the Arabs has manifested itself during the Abbasids period. The works of ancient cultures were translated into Arabic in the translation center called Beytu'l-hikme, which was established to carry out translation activities during this period. In this context, it has given information about translation activities, the meaning of the translation word, the time period it appeared, the reason for its emergence and also three major translation movements is mentioned.
\end{abstract}

Structured Abstract: Translation, which is a multidimensional and complex phenomenon, is a communication tool that is encountered in every era which acts as a bridge in communication between civilizations thus, eliminating the concept of alienation among people who transfer their history and traditions to the target language. Translation activity is an important need that has been done since ancient times and continues today. In the course of history, the societies contact with each other for trade, conquests and many other reasons caused the need to communicate and they fulfilled this need through translation. Thus, the translation studies which started on a small scale in the oldest civilizations of history were seriously in demand

\footnotetext{
* Dr. Öğr. Üyesi, Bartın Üniversitesi, Edebiyat Fakültesi, Çeviribilim Bölümü, Arapça Mütercim Tercümanlık Anabilim Dalı

Asst. Prof. Dr., Bartın University, Faculty of Literature, Department of Linguistics, Division of Arabic Translation and Interpreting

ORCID 0000-0002-5923-3920

blkbamehmet@gmail.com

Cite as/ Atıf: Bölükbaşı, M. (2020). Arap dünyasında tercüme faaliyetleri, Turkish Studies - Social, 15(3), 1005-1015.

https://dx.doi.org/10.29228/TurkishStudies.42171

Received/Geliş: 16 March/Mart 2020

Accepted/Kabul: 25 April/Nisan 2020

Copyright $($ INTAC LTD, Turkey

Checked by plagiarism software

Published/Yayın: 30 April/Nisan 2020

CC BY-NC 4.0
} 
with the acceleration of conquests, and finally reached the summit for five centuries which was dominated by the Abbasid State, known as the most brilliant and literary period of Arab Literature.

The need for translation has made it necessary for the translators to be trained and translators from different religions and sects have translated Greek, Persian, Hindi and Nebatian works into Arabic. The translation word is equivalent to the word 'Terceme' (التَََّْْمَة) which is an Arabic word. Looking at the dictionary meaning of the word. Translation; is the transfer and transfer of something, situation or meaning from one place to another from one state to another. Also translation; it can also be defined as the process of converting the material in the source language to the equivalent material in the target language. The need for translation has increased with the onset of human history and accordingly the emergence of different languages. Considering that the languages appeared 100,000 years ago and the writing was discovered 5000 years ago, the translation can be said to be quite ancient. Translation activity is as old as human history the first sources about translation studies was written in $3000 \mathrm{BC}$.

The emergence of translation is considered as the result of language diversity and people's need for communication. The importance of translation has been understood from the beginning of human civilization and has been used to communicate with people of different languages and cultures. Translation is a transfer attempt that is equivalent to history, trying to eliminate the communication confusion caused by the foreign language barrier. There is a chapter in the Torah on the emergence of various languages and accordingly the need for translation. In this section, the story of the Tower of Babel takes place. According to this story, people who turn to heresy after Noah's Flood decide to build a tower to realize their desire to reach the sky since they all speak the same language, they start building the tower with ease and unity. However, God creates a confusion between them to punish. In this way people who cannot get along with each other stop giving up this tower project with the existence of different languages, different cultures and people who adopted this culture emerged over time and this situation has prompted people to learn languages other than the language they speak.

In history, three cultural transfers are mentioned. These cultural transfers are the transfers that form the basis of the translation. The first of these is that Greek thinkers such as Pythogores and Plato who emerged in West Asia, west of the Aegean region and in the Mediterranean, know Mesopotamian, Iranian and Indian cultures closely and transfer them to Greek thought. The second cultural transfer started in the $7^{\text {th }}$ century and is the brightest period in the history of Arabic Literature where the works of Greek, Persian, Hindi and Nabatian were translated into Arabic, and it was the five centuries ruled by the Abbasid State. The third and last cultural transfer is the translation of Arabic works into Latin and Hebrew. This latest cultural transfer is known as the Toledo Movement. The conquest of the centers that prepared the ground for the initiation of translation activities by the Arabs caused the necessity to get to know those cultures closely and the issue of transferring the works belonging to these cultures into Arabic has been brought to the agenda. These centers were the centers where Hellenistic culture spread to the world and where the academies of Alexandria, Harran, Cundişapur, Antakya and Urfa were located.

The first translation activities in the Arab world began officially during the Umayyad period and were limited to personal pursuits. Translations in Arabic during the Umayyads were translations to meet general and instant needs in managing non-Arab people. Therefore, it is not possible to mention a serious translation activity in this period, translation activities gained momentum with the Abbasid State established after the fall of Umayyad with the Abbasid State taking over and the capital of the caliphate was moved from Damascus to Baghdad.

The new capital of the Abbasid State Baghdad, was a city with many cultures and being on the trade routes meant contact with many cultures. In such an environment, there was a need for information that would work in practice. The desire to learn different cultures has increased support for translation in the Abbasid society. In addition, the important centers where the Greek culture spread in the region called Bilâdu'ş-Şam were important for the Abbasid State which was newly established and had an innovative understanding because educational institutions where Hellenistic culture spread to the world were located here. Therefore, the acquisition of resources belonging to this culture to the Arab world was in support. The Abbasid society learned how to make paper from Chinese captives captured during the Talas war (751) which met the paper that made it possible for information to spread during conquests. Thus, the need for materials that helped the translation activities spread.

Turkish Studies - Social, 15(3) 
Keywords: Translation, major translation movements, Beytu'l-hikme, the important cultural centers.

Öz: Çeviri, insanoğlunun var olduğundan beri yapılan bir faaliyettir. Farklı bir dilden ana dile tercüme, karmaşık ve zor bir süreçtir. Tercümede önemli olan, çevrilmiş metni hedef dile en yakın anlamıyla çevirmektir. Çeviriyi etkileyen birçok faktör vardır bunların en önemlisi tercüme edilen çalışmanın yazıldığı kültürü bilmek ve onu, en uygun kelimeyi bularak hedef dile aktarmaktır. Tercüme, günümüzde de süregelen bir faaliyettir. Tarih boyunca toplumlar arasında iktisadi, kültürel ilişkiler ve fetihler aracılığıyla iletişimi sağlamak için tercüme ihtiyacı ortaya çıkmıştır ve aralarındaki iletişimi çeviri sayesinde sağlamışlardır. İnsanoğlu var olduğu zamandan itibaren, tercümenin önemli olduğunun farkına varmış ve diğer kültürlere mensup toplumlarla anlaşmak için tercümeden faydalanmıştır. Tercüme faaliyetleri, farklı dil ve kültürler arasında meydana gelebilecek anlaşmazlığı gidermek amacıyla M.Ö. II. asırda ortaya çıkmıştır. Araplarda ise; tercüme faaliyetlerinin ilk temelleri Emevîler döneminde, devleti yöneten kişilerin kişisel merakı sayesinde atılmıştır. Bu dönemde, tercüme faaliyetleri sadece devlet adamlarının çeviriye olan ilgilerinden öteye gidememiştir. Eski dönemlere ait, tarih eserlerinin çevirisinin yapıldı̆̆ı bir dönem olmuştur. Araplarda, tercüme faaliyetlerinin gelişimi Abbâsîler döneminde kendini göstermiştir. $\mathrm{Bu}$ dönemde, tercüme faaliyetlerinin yapılması amacıyla kurulan Beytu'l-ḥikme adı verilen tercüme merkezinde, kadim kültürlere ait eserler Arapçaya tercüme edilmiştir. Bu bağlamda çeviri faaliyetleri, çeviri kelimesinin anlamı ile ortaya çıktığı zaman dilimi, çıkış sebebi ve üç büyük çeviri hareketi hakkında bilgi verilmiştir.

Anahtar Kelimeler: Tercüme, başlıca çeviri hareketleri, Beytu'l-ḥikme, önemli kültür merkezleri.

\section{Giriş}

Çeviri faaliyeti insanlık tarihi kadar eskidir. Çeviri çalışmaları ile ilgili ilk kaynaklar M.Ö. 3000 yılında yazılmıştır. Çevirinin, toplumlar arasında ticari, sosyal ve diğer kültürel etkileşimler sonucu ortaya çıktığı kabul edilir. Çevirinin, toplumlar arası iletişimi sağladığı için önemli bir faaliyet olduğu anlaşılmıştır. Bu bağlamda, iletişimi sağlamak amacıyla çeviri faaliyetlerinin temelleri M.Ö. II. asırda atılmaya başlanmıştır. Eski zamanlardan beri var olan çeviri, herhangi bir dilde yazılmış kaynak metnin anlamında bir değişikliğe yol açmadan kelimeleri hedef metne benzer şekilde aktarma faaliyetidir (Aissi,1987:4).

Çeviri kelimesi, Arapça bir sözcük olan 'Terceme' (التَّْْجَمَةُة) kelimesinin karş1lığgdır. Çevirinin, sözlük anlamı bir metnin ya da bir durumun herhangi bir dilden, başka bir duruma aktarılmasıdır. Bununla birlikte; kaynak dildeki metnin hedef dile çevrilmesi faaliyetidir (Ülken, 1997: 14).

Tercüme kelimesi, klasik dönemlerde “çeviri” anlamında kullanılmamıştır. Bunun yerine; el-Câhiz'in (ö.869) Kitâbu'l-Hayevân adlı eserinin birkaç yerinde, çeviri sözcüğünün yerine "Naḳl (تَقَّ) velimeleri kullanılmıştır (el-Câhiz, 1979, I: 75-78). Bu bağlamda; İbnu'nNedîm (ö.995) tarafından telif edilen el-Fihrist ile diğer klasik eserlerin çoğunda çeviri sözcüğü

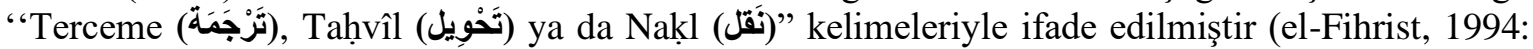

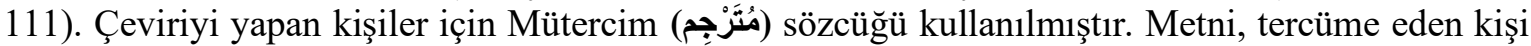
anlamına gelen Mütercim (مُنَّزْجم) sözcüğ̈̈; İbn Manzûr (ö.1311) tarafından telif edilen Lisânu'l-Arab

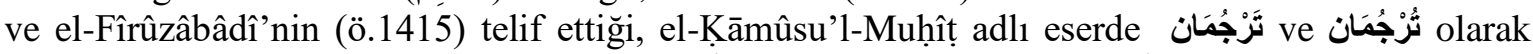
belirtilmiştir. Daha sonra bu kelimeler, مُنَّْجِم şeklinde kullanılmıştır (İbn Manẓûr, I, 426; elFîrûzâbâdî, IV.82).

\section{1. Üç Büyük Tercüme Hareketi}

Tercümede, bir durumun veya anlamın bir dilden başka bir dile aktarılması söz konusudur. Teknik anlamda "tercüme faaliyetleri" medeniyetlerin ve kültürlerin birbirleriyle karşılaşıp etkileşim kurmaları sırasında, belli bir birikime sahip eserlerin karşılıklı olarak nakledilmesidir. Arap dünyasında tercüme faaliyetleri, özellikle VIII. ve X. yüzyılları içine alan dönemde köklü ve eski 
kültüre sahip medeniyetlere ait eserlerin Arapçaya aktarılması şeklinde olmuştur. Bu aktarım sayesinde, Arap kültürü diğer kadim kültürler ile etkileşim içerisine girmiştir. Dünya tarihinde üç önemli kültür etkileşimi ve aktarımı meydana gelmiştir. Bu bağlamda; üç büyük tercüme hareketi ortaya çıkmıştır. İlk tercüme hareketi, M.Ö. 600'lü yıllarda başlamış daha sonra Sümerler, Fenikeliler ve Mısırlılar gibi medeniyetlere ait önemli eserler Grekçeye tercüme edilmiştir. Bu tercümeler sayesinde, kendine özgü niteliklere sahip bilim ve düşünce atmosferi oluşmuştur. Grek düşüncesinin sadece Grek aklının ürünü olmadığı; aksine kendisinden önce gelen antik düşüncelerden beslenen bir kültürlerarası etkileşim olduğu görülmektedir. İkinci tercüme hareketi, Arap-İslâm dünyasında VIII. ve IX. asırları kapsayan dönemlerde Süryânîce, Grekçe ve Pehlevîceden Arapçaya yapılan tercümelerdir. Üçüncü tercüme hareketi ise; XII. asırda Avrupalıların Arapça eserleri başta İbrânîce, Latince ve diğer Batı dillerine aktardıkları zaman dilimidir. Her üç çeviri faaliyetinde de kültürler arası iletişim ve etkileşim artmış; daha sonra belirli eğitim merkezlerine öğrenci gönderilmesiyle süreç devam etmiş̧iir. Bu üç tercüme faaliyetinin sonucu olarak belli bir sisteme sahip, kendine ait kuralları olan teknik metin çevirisi disiplini meydana gelmiştir (Ülken, 1997:28-30).

\subsection{Fetih Hareketlerinin Tercüme Faaliyetlerine Etkisi}

VII. asrın sonunda İslâm fetihlerinin hız kazanması sonucu, Müslümanlar kadim kültürlerle karşılaşmışlardır. 641 senesinde Mısır'ı yönetimi altına alan Amr b.Âs'tan (ö.664) itibaren, Büyük İskender'den bu yana Yakındoğu coğrafyasına egemen olan Helenistik kültür Pers ve Bizans hâkimiyetinden çıkmıştır. Bu sayede; Mısır, Suriye ve Bâbil Müslümanların eline geçmiştir. 651'de Merv ve Horasan ele geçirildikten sonra, Sâsânî İmparatorluğu ortadan kaldırılmıştır. İslâmiyet gelmeden önce Bizanslılar ve Persler arasındaki savaşlar ile Mısır, Suriye Râfizî monofizitleri ${ }^{1}$ ve Keldâni Ortodoksları arasında devam eden çatışmalar, bölgede yaşayanların hem huzursuz hem de güç kaybetmelerine sebep olmuştur. İslâm dinindeki hoşgörü sayesinde Müslüman-Arap yöneticiler kadim bilgilerin öğretildiği bilim merkezlerinde, büyük bir kısmı Hıristiyan olan Ya'kūbî ve Nestûrî’ âlimlerin bilimsel çalışmalarına devam etmelerine izin vermişlerdir. Bu yüzden, Arap-İslâm fetihleri o bölgede yaşayan yerel halk tarafindan Bizanslılardan ve Perslerden kurtuluş vesilesi olarak görülmüştür (Libera, 2005: 65).

\section{2. Önemli Kültür Merkezi İskenderiye}

İlim ve felsefe alanında çalışmaların devam ettiği merkezlerden birisi de İskenderiye idi. İskenderiye, 331 senesinde Makedon kralı Büyük İskender tarafından Helenistik kültürü oluşturmak amacıyla kurulmuştur. Büyük İskender'in ölümünden sonra, II. Batlamyus'un çabaları neticesinde; İskenderiye Yahudi ve Hıristiyan felsefesi ile Eflâtun, Aristo, Epikuros, Stoa ve ayrıca Yeni Eflâtun ile ilgili öğretilerin verildiği merkezlerden biri haline gelmişti. Ayrıca İskenderiye Asya, Afrika ve Avrupa'yı birbirine bağlayan yolların kesişme noktasında bulunan önemli bir ticaret, ulaşım ve kültür merkeziydi. Müslüman Araplar VII. asırda, felsefe ve ilahiyat konularının Grekçe öğretildiği önemli bir yer olan İskenderiye'yi fethetmişlerdi. (Doru, 2007: 43).

\subsection{Antakya, Urfa ve Nusaybin Okulları}

Antakya Okulu M. IV. asırda Antakya Psikoposu Justasius tarafindan İskenderiye okulu tarzında kurulmuştur. Bu okul, Yunan bilim ve kültürüne ait eserlerin incelendiği bir merkez olarak ön plana çıkmıştır. Bununla birlikte; Grekçe yazılmış eserlerin Süryânîceye tercüme edildiği ayrıca felsefî ve dini çalışmaların yapıldığı, ünlü bir yer haline gelmiştir. Daha sonra Arap-İslâm fetihleri neticesinde Emevi Halifesi Ömer b. Abdulazîz (M.717-720) döneminde, ikinci kültür merkezi kabul edilen "Antakya Okulu" olarak adlandırılan İskenderiye okulu Antakya'ya taşınmıştır (Mayerhof, 1965: 69).

\footnotetext{
${ }^{1}$ İnsanî ve ilâhî özelliklerin herhangi bir değişime uğramadan Hz. İsa'da var olduğuna inanılması düşüncesidir.
} 
Urfa ve Nusaybin okulları ise, 363 yılında Hıristiyanlaşmış olan İranlılara Yunancayı öğretmek maksadıyla Sâsânî ve Pers krallarınca kurulmuştur. Urfa'da yüzyıllarca Aristo ve Yeni Eflâtun ile ilgili metinler Grekçe okutulmuş, V. asrın sonlarında ise eğitimde Grekçenin yerini Süryânice almıştır. Ya'kūbîler ve Nestûrîler arasında patlak veren anlaşmazlıklar sonucu, Urfa'da bulunan okulda 489 yılında eğitime son verilmiştir. Bu durum üzerine, okulda ders veren hocaların bir kısmı Nusaybin'e giderek burada, Urfa'daki okulun devamı niteliğinde bir eğitim merkezi açmışlardır. IX. asra kadar eğitim veren, Nusaybin'deki okulda Aristo mantığı, Hipokrat ve Câlînûs'un tıp kitapları okutulmuştur (O’leary,1962:68).

\subsection{Cundişâpûr Okulu}

Sâsânî Hükümdarı I. Şâpûr tarafindan Rum esirleri bir merkezde tutmak amaciyla kurulan Cundişâpûr, daha sonra Sâsânî Hükümdarlarından I. Hüsrev'in (Enûşirvan) (531-579) açmış olduğu, felsefe ve tıp okulu sayesinde hatırı sayılır bir eğitim merkezi olmuştur. Ayrıca 529 yılında Bizans İmparatorlarından Iustinianos'un Atina' daki felsefe ve bilimler okulunu kapatması sonucu, buradaki ilim adamlarının bir kısmı Cundişâpûr'a yerleşmiştir (İbn Ebû Usaybia, 1965: 183). Bu iki etken sayesinde bilimsel çalışmaların hız kazandığı bir merkez haline gelen Cundişâpûr'da, ilk önce I. Hüsrev döneminde Aristo ve Eflâtun tarafından telif edilen bazı kitaplar ile insanlara öğüt vermek amacıyla Hintçe yazılmış olan Kelîle ve Dimne adlı eser Farsçaya tercüme edilmiştir (O’leary,1972:41). Tıp okulunda ise; Hintli ve Yunanlı hekimler çalışmıştır. Bu okuldaki çalışmalar daha sonra Arap-İslâm dünyasında, tıp kültürünün oluşmasına büyük katkı sağlamıştır. Bu bağlamda Cundişâpûr, Suriye, Hindistan, Yunanistan ve İran kökenli ilim adamlarının bir araya geldiği önemli bir bilim merkezi haline gelmiştir. Ayrıca; felsefe ve tıbbî bilimlerin bölgede öğretilmesinde ve aktarılmasında önemli rol oynamıştır (Sayıl1, 1980: 112).

Cundişâpûr M.638 senesinde Müslüman Arapların yönetimine geçmiş, daha sonra zaman içerisinde rasathane, tıp okulu ve akademisi ile ünlenmiştir. Cundişâpûr'un hem Bağdat'a yakınlığı hem de İranlıların Abbâsîlerle kurdukları iyi ilişkiler ve ayrıca Cundişâpûr'da bulunan okul sayesinde, ilmi ve felsefî gelişmeler Arap-İslâm Coğrafyasının her yerine yayılmıştır. Bu bağlamda, Cundişâpûr'da M. 765 senesinde hastanenin idarecisi Curcîs b. Cibrâîl b. Buhtîşû, Bağdat'a çağrılarak Halife Ebû Ca'fer el-Mansûr'u tedavi etmesi istenmiştir. Ayrıca Mâseveyh, Tayfûrî ve Buhtîşû́ aileleri de uzun seneler boyunca halifelere hekimlik yapmışlardır (İbn Ebû Usaybia, 1965: 184).

\subsection{Sâbiîler'in Kültür Merkezi Harran Okulu}

Bir diğer kültür merkezi ise; Sâbiîler'in ilmi çalışmalar yaptı̆̆ 1 Harran idi. Makedon Kralı Büyük İskender (ö. m.ö. 323) Harran'1 ele geçirdikten sonra, Yunanlı birçok ilim adamı Harran'a yerleşerek kültürlerini burada yaymaya başlamışlardı. Bu sayede, Büyük İskender döneminden İslâm devrinin başlarına kadar Harran'da Hermetik-Helenik kültür egemen olmuştu. Ayrıca, bu okulda astronomi ve matematik bilimleri alanında önemli çalışmalar yapılmaktaydı. Bununla birlikte; Harran'da matematik, felsefe, tıp ve astronomi alanında eğitim alan ilim adamları, Abbâsîler'in ilk devirlerinde tercüme ve telif alanlarında önemli çalışmalar yapmışlardır. Bu ilim adamlarından tercüme alanında ön plana çıkan kişi Sâbit b. Kurre'dir (Emîn, 1969: 259).

\subsection{Bağdat Okulu}

Abbâsîler' in ikinci halifesi olan Mânsur, (754-775) bu ilim merkezlerinin en önemlisi olan Bağdat'1 762 yılında kurmuş ve burayı başkent yapmıştır. Bağdat kurulduktan sonra hızlı bir gelişme göstermiş IX. ve X. asırlarda Arap-İslâm dünyasının ilim, kültür, medeniyet ve en büyük şehri haline gelmiştir. Bağdat, kurulduktan bir asır sonra İran ve Hint medeniyetlerine ait eserler ile daha önce Pehlevîceye çevrilmiş olan Grekçe metinler tercüme edilmiştir. Bu sayede Bağdat, Güney Avrupa'y1 Ortadoğu ve Yakındoğu ile bir araya getirmeyi başarmıştır. Halife Mansûr ve Hârûnurreşîd'in vezirliklerini yapan Bermekîler'in, teşvik etmesi sayesinde Süryânîler ve Harranlılar, Hellenizm 
merkezlerinden biri olan Cundişâpur'dan, Bağdat'a gelerek tercüme faaliyetlerine katılmış; Yunanca, Pehlevîce, Sanskritçe ve Süryânîce telif edilmiş kitapları Arapçaya tercüme etmişlerdir. Bu bağlamda, kültür merkezleri sayesinde Helenistik felsefe ile Hint ve Sâsânî kültür mirası Arapİslâm dünyasına intikal etmiştir (Fahrî, 1992: 37).

\section{Tercüme Hareketlerinin Temel Etkenleri}

Tercüme faaliyetlerinin faktörleri ile ilgili birçok etken vardır. Bu etkenleri ise; sosyal, ekonomik, siyasal ve ideolojik olarak sıralamak mümkündür. Müslüman Arapların, fikri dünyasına șekil veren temel unsur ilme ve evrensel kültüre ayrım yapmadan değer vermiş olmalarıdır. Bu bağlamda; Hz. Muhammed'in, "Hikmet müminin yitik malıdır" hadisi şerifinde ve Kur'an-1 Kerim'de de farklı milletlerle tanışıklık kurulmasının önemine değinilmiştir (el-Hucurât 49/13). Bununla birlikte; Müslüman Araplar kültürler arası etkileşime teşvik edilmiş, bu sayede tercüme hareketlerinin oluşumuna katkı sağlanmıştır. Arap dünyasında, farklı disiplinlerin ortaya çıkması ve sistemleşmesi de daha önceki ilimlerin göz önünde bulundurulmasını zorunlu kılmıştır. Bununla birlikte; fetihler sayesinde sınırları genişleyen Arap-İ́slâm devletinin ihtiyaçları artmış, bu yüzden bazı kurumların kurulması bilgi ve tekniklerin öğrenilmesi gerekliliği ortaya çıkmıştır. Müslümanlığın ortaya çıktığı ilk senelerde Arap yarımadası, fethedilen diğer coğrafyalara göre kurumsal, bilimsel ve düşünce açısından geri konumdaydı. Ayrıca Arapların ihtiyaç duydukları bilim ve kültür, kadim milletlerde bulunmaktaydı. Bu bağlamda; öncelikle Abbâsîler devrinde âlimler; önce Grek ve Antik Çağ Yunan kültürlerinde, oldukça iyi bir seviyede olan matematik, tıp ve astronomi alanlarında incelemeler yapmışlardır (Ulukütük, 2010: 249). İbn Kuteybe (ö.889) tarafından telif edilen "Edebu'l-Kâtib" adlı eserde bu durum şöyle açıklanmıştır: "Bir ilim adamının geometrik şekilleri bilmesi zaruridir. Ancak bu sayede arazi ile ilgili gerekli ölçümleri yapabileceği belirtilmiştir (İbn Kuteybe, 1988: 6).

Tercüme faaliyetlerini etkileyen bir diğer husus ise; Hıristiyan âlimleri ile Müslüman âlimler arasında meydana gelen dini ve felsefî tartışmalar esnasında, Hıristiyan âlimlerin fikirlerini savunmak için Eski Yunan filozoflarının görüşleri ve Aristo mantığından faydalanarak cevaplar vermeleridir. Bu durum Müslüman âlimlerde kendi düşüncelerinin ve İslâm dininin Hıristiyanlık inancindan üstün olduğunu ispatlamak amacıyla, "eski medeniyetlere ait önemli bilgiler içeren eserleri Arapçaya tercüme etmenin gerekli olduğu" düşüncesini uyandırmıştır. Tercüme faaliyetlerini etkileyen bir diğer unsur, jeopolitik hareketlerdir. Bu bağlamda, bilim ve felsefe Sümerler, Fenikeliler ve Misırlılardan antik Yunan'a intikal etmiştir. Felsefenin; Fenikeliler, Misırlılar, Persler ve Keldânîler gibi kadim milletlerden Yunanlılara intikal ettiği, ama felsefenin kaynağının Yunanlılar olduğu vurgulanmıştır (Laertious, 2003:13). Fakat Yunanlılar ile diğer kültürler arasında hiçbir etkileşimin bulunmaması ve felsefenin kaynağının sadece Yunanlılar olarak kabul edilmesi, doğru bir görüş değildir çünkü Yunanlılar ile diğer kültürler arasında hiçbir etkileşimin bulunmaması imkânsızdır. Örneğin; Zerdüşt öğretilerine dair telif edilmiş olan “'Kitabu'l-Mevâlîd”' adlı eserde Makedon Kralı Büyük İskender'in ele geçirdiği bölgelerde astroloji, astronomi, tıp ve diğer bilimlere ait eserleri Yunancaya tercüme ettiği belirtilmiştir (Laertious, 2003: 41). Felsefî ilimler; Keldânîlerden Mısır'a, Misır'dan da Yunanlılara, Yunanlılardan da Süryânîlere ve Araplara intikal etmiştir (el-Fârâbî, 2003:54). el-Câhiz'e göre; kadim mirastan kabul edilen Hint kitapları, Yunan eserleri ve Fars edebiyatı Arapçaya tercüme edildi. Bu tercümelerin bir kısmı oldukça iyi, bir kısmı ise kusursuz denilebilecek mükemmellikte tercüme edilememiştir. Kadim milletlere ait eserler dilden dile aktarılarak, bizlere kadar ulaşabilmiştir. Bizim ise, eski milletlerden kalan eserleri inceleyip, faydalananların sonuncusu olduğumuzu ifade etmiştir (el-Câhiz, 1979: I, 75).

Dilden dile aktarılan kadim milletlere ait eserlerde olduğu gibi öğretim merkezleri de bir coğrafyadan diğer coğrafyaya intikal etmiştir. İlkçağ ve Ortaçağ'da öğretim merkezleri coğrafi olarak yer değiştirmiştir. Bu coğrafi hareketler ilk olarak Atina'da başlamış daha sonra İran'a geçmiş 
İran üzerinden Harran'a intikal etmiştir. İkinci hareket; İskenderiye'de ortaya çıkmış daha sonra VII. ve VIII. yüzy1llarda Suriye'ye geçmiştir. Üçüncü hareket ise; Süryânîlerden Araplara, diğer bir deyişle İskenderiye'den Bağdat'a, Bağdat'tan sonra Kurtuba'ya ve Toledo'ya geçmiştir. Bu sayede Hıristiyan dünyası derin uykusundan uyanmıştır (Libera, 2005:89).

Araplarda tercüme faaliyetleri sistemli bir şekilde, Abbâsî Halifesi Mansûr (754-775) döneminde Beytu'l-hikme'nin ilk temelleri atılarak ortaya çıkmıştır. Halife Mansûr tarafından başlatılan tercüme faaliyetleri daha sonra gelen Abbâsî Halifeleri tarafindan da desteklenmiştir. Bununla birlikte; Abbâsîler devrinde kurulan Bağdat şehri Abbâsî devletinin bilim ve siyaset jeopolitiğinin hayata geçirilmiş halidir. Bu durum tercüme faaliyetleri için oldukça önemlidir. Halife Mansûr Bağdat şehrini kurarken Sâsânî İmparatorluğunu örnek almıştır. Abbâsîler devrinde kurulan Bağdat şehri Sâsânîlerin Başkenti Ktesifon'un kurulduğu yerin yakınlarına inşa edilmiş, Öklid'in "Ușûlu'l-hendese" isimli kitabındaki daire tanımı göz önünde bulundurularak merkezde bulunan yerleşimlerin diğer bölgelere eşit uzaklıkta kurulmalarına önem verilmiştir. Bağdat'ın kuruluş tarihi saray müneccimlerine danışılmış ve şehrin kapıları kadim medeniyetlerin kalıntılarından bulunarak getirilmiştir (Gutas, 2003: 42).

\section{Emevîler Devrinde Tercüme Faaliyetleri}

Emevîler fetih hareketleri neticesinde farklı kültürlere sahip toplulukların yaşadıkları toprakları yönetmeye başlamışlardır. Hüküm sürdükleri toprakların çoğunda Yunanca kullanılmaktaydı. Bu bağlamda; Emevîler, Halife Abdülmelik'in yönetimde kaldığı 685 ile 705 yılları arasında devlet idaresinde Yunancayı kullanmış ve malî işlerini yürütmek amacıyla Bizans İmparatorluğu ile ilişkisi olan kişilerden yararlanmışlardır (Suçin, 2012: 28)

Bu gelişmeler Emevîler döneminde Yunancadan Arapçaya tercümelerin yapılmasını zorunlu kılmıştır. Emevîler, ilk dönemlerinde devlet işlerinin devam edebilmesi ayrıca ticari, sosyal ve kültürel alandaki ihtiyaçlar ile yöneticiler ve halk arasındaki iletişimi sağlamak amacıyla, Yunanca tercüme yapabilecek kişilere resmi görevler vermişlerdir. Bu dönemde yapılan tercümeler bilimsel değildi, daha çok Arap yöneticiler ile Arapça bilmeyen halk arasındaki iletişimi sağlamak maksadıyla yapılan çevirilerdi. Bu çeviriler, belli bir sisteme ve plana dayanmıyordu. Emevîler devri, tercüme faaliyetlerinin temellerinin atıldığı bir nevi hazırlık dönemidir çünkü bu dönemde çeviri olgusu devlet adamlarının kişisel çabaları sayesinde bir ilerleme kaydedebilmiştir. Bu bağlamda; Arap dünyasında tercüme alanında ilk olgular, Emevîler devrinde kendini göstermeye başlamıştır. Emevî halifesi Hâlid b. Yezîd (ö.704 ) diğer ilimlere karşı merakı olduğundan Arapçaya hâkim Grek filozoflarından bir kısmını Mısır'dan getirterek, Grekçe ve Kıptîce telif edilmiş Kimya kitaplarını Arapçaya tercüme ettirmiş̧ir. Bu durum, Arap dünyasında başka dilden Arapçaya yapılan ilk tercüme faaliyeti olarak kabul edilir. Emevîler devrinde, yapılan tercüme faaliyetleri belli bir sisteme ve disipline bağlı değildi. Daha çok kimya, tıp ve astronomi gibi alanlardaki ihtiyaçları gidermek amaciyla yap1lıyordu. (İbnu'n-Nedîm, 1994: 338).

Emevî halifeleri arasında ilk tercüme Emevîlerin kurucusu Muaviye b. Ebi Süfyan (661-680) tarafından yapılmıştır. Bu bağlamda; Muaviye b. Ebi Süfyan Tıp ile ilgili bir kitap telif edilmesini isteyerek, İbn-i Asal'a (666) bir tıp eseri telif ettirmiştir. İbn-i Asal, telif ettiği “"Müfred ve Mürekkeb İlaçlar ve Kuvvetleri”" isimli eserinde, birçok Yunanca ve Süryânîce telif edilmiş kitaptan yararlanmıştır Bu bağlamda; Emevîler döneminde, çeviri faaliyetleri Emevî halifelerinin ilme karş1 ilgileri ve merakı sayesinde devam etmiş ve bu çabalar tercüme faaliyetlerinin altyapısının hazırlandığı bir zaman dilimi olmuştur. Bu dönemde yapılan çeviriler idari, mali ve sosyal hayatta karşılaşı1lan problemleri çözmek maksadıyla yapılmıştır (Aycan, 2000:217).

\section{Abbâsiler Devrinde Tercüme Faaliyetleri}

Arap dünyasında tercüme faaliyetleri tam manasıyla Abbâsiler devrinde başlamıştır. $\mathrm{Bu}$ devirde, tercüme faaliyetleri kişisel gayretlerin ötesinde artık devlet politikası haline gelmiştir. Bu 
bağlamda; felsefî ve ilmî eserler belli bir disiplin içerisinde Arapçaya tercüme edilmiştir. Abbâsilerin ikinci halifesi Ebû Ca'fer el-Mansûr devrinde İranlı İbnu'l-Mukaffa', Aristo tarafindan telif edilen Organon adlı eserin ilk üç kitabı ile Kelîle ve Dimne adlı eseri Farsçadan Arapçaya çevirmiştir. Bununla birlikte, yine Hint astronomisinin ünlü eserlerinden olan Sind-Hind, ${ }^{2}$ Ptolemeus'un elMecisțî ile Öklid'in Ușûlu'l-hendese ${ }^{4}$ adlı eserler tercüme edilmiştir. Halife Mansûr'un oğlu MehdîBillâh döneminde, dinî tartışmalar tercümelere yön vermiştir. Bu bağlamda, Mehdî 782 senesinde Nestûrî patriği I. Timotheus ve ekibine Aristo tarafından telif edilen "Kitâbu'l-Cedel" adlı eseri tercüme ettirmiştir. Hârûnurreşîd (786-809) devrinde ise; Bizans topraklarının bir bölümünün ele geçirilmesi ile elde edilen Grekçe eserlerin bir kısmı Bağdat'a getirilerek, Yuhannâ b. Mâseveyh'in başkanlığını yaptığı bir heyet tarafından Arapçaya tercüme edilmişlerdir. Abbâsiler devrinde, sistematik anlamda tercüme faaliyeti Halife Me'mûn döneminde başlamıştır. Halife Me'mûn Bağdat'ta 830 yılında Beytu'l-hikme isminde ilmî ve tercüme çalışmalarının yapıldığı bir merkez kurmuştur (İbnu'n-Nedîm, 1994: 345).

Klasik kaynaklarda, Halife Me'mun'un (ö.833) rüyasında Aristo’yu gördüğü ve Aristo'nun, Me'mun'a iyinin ne olduğu hakkında sorular sorarak cevaplar aldığı belirtilir. Bu rüya üzerine Halife Me'mun, Bizans'tan Grek filozoflarının telif ettiği eserleri getirterek, Grekçeden çeviriler yaptırmaya başlamıştır. Bu bağlamda; Abbâsîler döneminin meşhur Süryânî hekimi olan Yuhannâ b. Mâseveyh (ö.857) bir heyetle birlikte İstanbul'a gönderilmiştir. Ancak Bizans o devirde, antik felsefeyle ilgilenmediğinden Grekçe eserlerden kimsenin haberi yoktu. Yuhannâ b. Mâseveyh (ö.857) ve beraberindeki heyetin girişimleri sonucu, İstanbul'a üç günlük mesafede bulunan bir tapınağın gizli bölümlerinde, toprağa gömülerek saklanan kitaplar bulunup Bağdat'a getirilmiştir (İbnu'n-Nedîm, 1994: 349).

\section{Tercüme Yöntemleri}

Eski Yunan tıp ve felsefesinin Arap-İslâm dünyasına aktarılmasında büyük katkısı olan mütercim ve hekim Huneyn b. İshâk (ö.873) ile heyeti, tercüme faaliyetlerinde metin tahkikine yakın tarzda karşılaştırmalı metin çalışmaları ve tercümeler yapmışlardır. Bu çalışmalar sayesinde, Arap dünyasında tercüme yöntemlerinin temeli atılmıştır. Bu bağlamda, Huneyn b. İshâk (ö.873) Aristo tarafından telif edilen 'Kategoriler' adlı eseri Yunancadan Süryânîceye ve daha sonra Süryânîceden Arapçaya tercüme etmiştir. Arap dünyasında başka dilden yapılan tercümeler, metinlerin birebir tercümesi şeklinde yapılmaktaydı. Yuhannâ b. Bıtrîk (ö. 815) ve İbn Nâime el-Hımsî (ö.835) gibi Abbâsi dönemi mütercimleri Yunanca metinleri birebir tercüme ediyorlardı. Huneyn b. İshâk (ö.873) ise, birebir tercüme etmek yerine tercüme ettiği dilin sözdiziminin dışına çıkmış; abartılı ve anlaşılmayan sözcüklerden kaçınarak cümlenin genel anlamını göz önünde bulundurmuştur. $\mathrm{Bu}$ yöntem, Arap dünyasında daha sonra yapılan tercümelerde kullanılmıştır (Libera, 2005: 93).

\section{Mısır'da Tercüme Faaliyetleri}

Yunan düşüncesiyle daha önce karşılaşmış olmalarına rağmen, Araplarda Batı dillerinden yapılan çeviriler ancak XIX. yüzyılda başlamıştır. Bununla birlikte; Batı etkisi kendisini Arap dünyasında iki şekilde göstermiştir. Bu durumun ilki, Lübnan'da yaşayan Hıristiyan Arap edebiyatçılarının çalışmaları ile ortaya çıkmıştır. İkincisi ise; Mısır'ın 1798 yılında Napolyon Bonapart tarafından işgal edilmesinden sonra Osmanlı Devleti'nin bu işgalden kurtulmak için Kavalalı Mehmet Ali Paşa'yı kullanarak, Fransızları Mısır'dan çıkarmasıyla başlamıştır. Napolyon'dan sonra, 1769 ile 1848 yılları arasında Mısır'a egemen olan Kavalalı Mehmet Ali Paşa (ö.1849) sahip olduğu ordunun ihtiyaçlarını gidermek için, birçok öğrenciyi burslu olarak yurt dışına göndermiştir. Bu sayede, yurt dışına gönderilen öğrenciler gittikleri ülkelerde okudukları metinleri,

\footnotetext{
${ }^{2}$ Gezegenlerin astronomik cetvellerini içeren bir kitaptır.

${ }^{3}$ Sintaksis veya Matematikis Sintaksis ismiyle anılan Astronomi ve Matematik kitabıdır.

${ }^{4}$ Geometri kitabidır.
} 
Arapçaya tercüme ederek yayınlamışlardır. Tercüme ve uyum sürecinin başlangıcında taklide dayanan edebî eserler ortaya çıkmıştır. Belli bir zaman sonra, gelişme kaydedilmiş daha özgün ve taklide dayanmayan eserler telif edilmiştir. Bununla birlikte; Kavalalı Mehmet Ali Paşa (ö.1849) tarafindan 1809 ile 1819 seneleri arasında daha çok esere ulaşmak amacıyla İtalya ve Fransa'ya gönderilen öğrenciler, bu ülkelerdeki eserleri inceleyip tercüme ettikten sonra Misır'a göndermişlerdir. Bu bağlamda; tercüme alanında öne çıkan önemli bir isim olan Rifâa et-Tahtâvî (ö.1873) Paris'e gönderilen öğrenci grubunda yer almaktaydı. Asıl görevi öğrenci grubunun imamlığını yapmak olan, Rifâa et-Tahtâvî, Paris'te Fransızca öğrendi ve mütercimlik eğitimi aldı. Paris'te farkl1 alanlarda yazılan eserleri inceleme firsatı buldu. Voltaire, Rousseau, Montesquieu ve Racine'in eserlerinden etkilenen et-Tahtâvî, bu eserlerden bazılarını Arapçaya tercüme etti. 1831 senesinde Mısır'a geri döndü. Paris'te iken tercümesine başladığı "Précis de Géographie Universelle" isimli coğrafya kitabının ilk cildinin tercümesini tamamladı. Kavalalı Mehmet Ali Paşa tarafından 1835 yılında kurulan tercüme okulunda görev yaptı. Mısır'da faaliyet gösteren Medresetu't-tercüme'nin adını Medresetu'l-elsun olarak değiştirdi (Cemaleddin eş-Şeyyal, 1950:29).

\section{Batı Dünyasında Arapçadan Latinceye ve İbrânîceye Yapılan Tercümeler}

Batıda, Arap dünyasının bilimsel çalışmalarına ve fikirlerine karşı merak, X. asrın sonları ve XI. asrın ilk başlarında yaşamış olan Papa II. Sylvèstre ile başlamıştır. Daha sonra ilk mütercim olarak görülen Afrikalı Konstantin, (ö.1087) Salerno Tıp Okulu'nda Arap-İslâm tıbbı hakkında Arapça telif edilmiş eserleri Latinceye tercüme ederek Arap-İslâm tıp anlayışını ve inceliklerini Batı dünyasına tanıtmış ve bu tercüme çalışmaları sayesinde, Arap dünyasıyla bilimsel ve kültürler ilişkiler gelişmeye başlamıştır. Üç asır boyunca Arapların hâkimiyetinde kalan Tuleytula (Toledo) 1085 senesinde İspanyollar tarafindan ele geçirilmiştir. Daha sonraki yıllarda Tuleytula'da (Toledo) Endülüs'ün İşbîliye (Sevilla) ve diğer şehirlerinde, Güney Fransa, Sicilya ve az da olsa Portekiz'de Arapçadan Latinceye tercümeler yapılmıştır. Bu bağlamda Toledo' da bir çeviri merkezi kuran ayrıca 1125 ile 1152 senelerinde başpiskoposluk yapan Raymond de Sauvetat, (ö.1152) II. Sylvèstre'ın yolunu takip ederek Müslüman, Hıristiyan ve Yahudi tercümanlardan faydalanarak Arap bilim ve düşüncesine ait eserlerin birçoğunu Arapçadan Latinceye tercüme ettirmiştir. (Karlığa, 2004:251).

Kastil Kralı Alfonso Sevilla'da (ö.1109) bir Arapça Okulu açarak, Kelîle ve Dimne, Sırru'lesrâr gibi kitapları Kastilceye çevirtmiştir. Yapılan çeviri faaliyetlerine Kastil Kralı Alfonso'da katılmış ayrıca İtalyan Yahudi filozofu ve tercümanı Juda ben Moses (ö.1330) ile Yahudi tercüman Samuel ha Levi (ö.1360) gibi mütercimlerde yardım etmiş̧lerdir. Bununla birlikte; Portekiz, Sicilya ve Güney Fransa'da tercüme faaliyetleri görülmekteydi. Özellikle Sicilya'da 1215 ve 1250 senelerinde krallık yapan II. Friedrich, (ö.1250) astrolog ve mütercim olan Michael Scotus'u (ö.1232) tercüme faaliyetleri için sarayında çalıştırmıştır. İngiliz düşünürü Abelard de Bath (ö.1142) Arap dünyasında önemli bir eser kabul edilen Muhammed b. Mûsâ el-Hârizmî (ö.850) tarafından telif edilen "Zîcu's-Sind-Hind" ve Öklid'in (M.Ö. 275) "Usûlu'l-hendese"' adlı eserleri Latinceye çevirmiştir (Karlığa, 2004:253). Yahudi mütercimler arasında ise; Samuel İbn Tibbon (ö.1232) ile oğlu Moses ben Samuel İbn Tibbon (ö.1274) yaptıkları tercümelerle ön plana çıkmışlardır. Moses ben Samuel İbn Tibbon; tıp, matematik ve felsefe alanında Arapça telif edilen kitapları İbrânîceye tercüme etmiştir (Kaya, 1983: 89-90).

\section{Sonuç}

Tercüme olgusu insanlığın var olduğu günden beri yapılan bir faaliyettir. Tercüme toplumlar arasında iletişimi sağlamak maksadıyla ortaya çıkmıştır. Farklı dilleri konuşan toplumların birbirleriyle anlaşması tercüme sayesinde gerçekleşmiştir. Tercüme faaliyetlerinin hızlanmasına ve belli bir disiplin içerisinde yapılmasına olanak sağlayan etkenlerden biriside, farklı coğrafyaların ele geçirilmesidir. Bu bağlamda; Araplar fetihler sayesinde farklı dillere ve inançlara sahip bölgelere hüküm etmeye başladıktan sonra, orada yaşayan halkla iletişime geçmek ve kültürlerini öğrenmek 
amacıyla, tercüme faaliyetlerine adım atmışlardır. Araplar, ilk tercümelerde daha çok malî, idarî ve günlük hayatta karşılaşılan problemleri çözmek maksadıyla tercümanlardan faydalanmışlardır.

Daha sonra Araplar, ele geçirdikleri bölgelerde yaşayan kadim milletlere ait astronomi, tıp, mantık ve felsefe alanında yazılmış eserleri Arapçaya tercüme ederken eserlerde, eksik ve yanlış yazılan bilgileri düzelterek bilim dünyasına kazandırmışlardır. Araplar tarafından, tercüme edilen bu eserlerden halen faydalanmaktayız. Araplar, tercümeler sayesinde Hint, Yunan, Süryânî ve Kıptî kültürlerini ve bilimsel çalışmalarını öğrenerek, bu kültürleri diğer toplumlara aktarabilmişlerdir. Buna ek olarak; Araplarla etkileşime giren toplumlar; Arapça telif edilmiş eserleri Latinceye ve diğer batı dillerine tercüme ederek Arap kültürünün ve düşünce yapısının Batı dünyasına aktarılmasında rol oynamışlardır. Farklı medeniyetler arasında yapılan bu tercüme faaliyetleri sayesinde, birçok değerli eser günümüze kadar gelebilmiştir. Bununla birlikte; Araplar, kadim toplumlardan kalan ve unutulmaya yüz tutmuş birçok önemli eseri Arapçaya tercüme ederek dünya kültür mirasına kazandırmışlardır.

\section{Kaynakça}

Aycan, İ. (2000). Emevîler Dönemi Kültür Hayatında Bazı Beşeri İlimlerin Tarihsel Gelişimi. Dini Araştırmalar 2.

Aissi, L. (1987). An Analytical Study of The Process of Translation (With Special Reference To English / Arabic), (Yayımlanmamış Doktora Tezi), Salford Üniversitesi Modern Diller Bölümü. İngiltere.

Cemaleddin eş-Şeyyal (1950). Târîhu't-Terceme fi Misr fi Ahd el-Hamle el-Fransiyye. Cairo: Daru'lFikr el-Arabi.

Doru, N. (2007). Doğu'dan Batı'ya Köprü Süryânîler Felsefe ve Çeviri Geleneği. Ankara.

Emîn, A. (1969). Duh'al-i̇slâm. Beyrut.

el-Câhiz, Ebu Osman Amr b. Bahr (1979). Kitâbu'l-Hayevân. (Nşr). Abdüsselâm M. Hârûn. Kahire.

el-Fârâbî, Ebû Nasr Muhammed b. Muhammed b. Tarhan b. Uzluğ et-Türkî (2003).Tahsîlu'ssaâde. (trc). Hüseyin Atay, İstanbul.

el-Fîrûzâbâdî, Ebû't-Tâhir Mecduddîn Muhammed b. Ya'kûb b. Muhammed (2005) el-Kâmûsu'lMuhît (thk.) Mektebu't-tahkîki't-turâsi fî müesseseti'r-risâle Beyrut: Müessesetu'r Risâle.

Fahrî, M. (1992). İslâm Felsefesi Tarihi. (Trc.) Kasım Turhan, İstanbul.

Gutas, D. (2003). Yunanca Düşünce Arapça Kültür. (Trc). Lütfü Şimşek, İstanbul.

İbn Manzûr, (1999). Lisânu'l-arab. Beyrut: Daru sâdır.

İbnu'n-Nedîm (1994).el-Fihrist. (Nşr.) İbrâhim Ramazan, Beyrut.

İbn Ebû Usaybia, Muvaffakuddîn Ebu'l-Abbâs Ahmed b. el-Kâsım. (1965). Uyûnu'l-enbâ fì tabakâti'l-etibbâ (Nşr.) Nizâr Ridâ, Beyrut: Dâru mektebeti'l-hayât.

İbn Kuteybe, (1979). Edebu'l-kâtib. (Nşr.) Hüseyin Varol. Atatürk Üniversitesi İslâmî İlimler Fakültesi: Erzurum.

Karlığa, B. (2004). İslâm Düşüncesi’nin Batı Düşüncesi'ne Etkileri. İstanbul.

Kaya, M. (1983). İslâm Kaynakları Işı̆̆ıında Aristoteles ve Felsefesi. İstanbul.

Laertious, D. (2003). Ünlü Filozofların Yaşamları ve Öğretileri. (Trc.) Candan Şentuna, İstanbul. 
Libera, A.D. (2005). Ortaçağ Felsefesi. (Trc.) Ayşe Meral. İstanbul.

Mayerhof, M. (1965). Mine'l-İskenderiyye ila Bağdat Bahsun fî Târihi't-Te'limi'l-Felsefì ve'tTibbî İnde'l-Arab. (Trc.) Abdurrahman Bedevî, Kahire.

O'leary, D.L.E. (1972).el-Fikrü 'l-Arabî ve Merkezuhu fi't-Târih. (Trc.) İsmail el-Baytar, Beyrut.

O’leary, D.L.E. (1962).Ulumu'l-Yunan ve Subul İntikâlihe ile'l-Arab. (Trc.) Vehib Kâmil, Kahire.

Say1l, A. (1980). The Emergence of the Prototype of the Modern Hospital in Medieval Islam. IV/2

Suçin, M.H. (2012). Dünden Bugüne Arapçaya Çevirinin Serüveni. Ankara.

Ulukütük, M. (2010). İslâm Düşüncesinde Tercüme Faaliyetleri, Hermeneutik ve Bibliyografik Bir Katk1, I. Ü. Illahiyat Fakültesi Dergisi.

Ülken, H.Z. (1997). Uyanış Devirlerinden Tercümenin Rolü. İstanbul. 